\title{
Optical properties upon vacuum ultraviolet excitation of sol-gel based $\mathrm{Y}_{3} \mathrm{Al}_{5} \mathrm{O}_{12}: \mathrm{Tb}^{3+}, \mathrm{Ce}^{3+}$ powders
}

\author{
A. Potdevin, G. Chadeyron, ${ }^{\text {a) }}$ D. Boyer, and R. Mahiou \\ Laboratoire des Matériaux Inorganiques, Université Blaise Pascal and ENSCCF, 24 Avenue des Landais, \\ 63177 Aubière Cedex, France
}

(Received 15 February 2007; accepted 31 July 2007; published online 12 October 2007)

\begin{abstract}
Optical properties in the vacuum ultraviolet (VUV) region of cerium and terbium activated $\mathrm{Y}_{3} \mathrm{Al}_{5} \mathrm{O}_{12}$ powders obtained by the sol-gel process were investigated at room and low temperatures. Both $\mathrm{Tb}^{3+}$ and $\mathrm{Ce}^{3+}$ doped samples exhibited a broad absorption band within the conventional Xe-Ne plasma emission range (140-190 nm). Optimal doping rates have been determined for both rare-earth ions. Emission spectra from cerium doped samples were recorded at $8.2 \mathrm{~K}$ and uncovered the splitting of the ground state of $\mathrm{Ce}^{3+}$ ions. Decay times of $\mathrm{Ce}^{3+}$ fluorescence can be fitted by double exponential curves, which can be ascribed to a retrapping phenomenon. Eventually, optical characteristics of codoped $\mathrm{Y}_{3} \mathrm{Al}_{5} \mathrm{O}_{12}:(\mathrm{Tb}, \mathrm{Ce})$ and $\mathrm{Y}_{3} \mathrm{Al}_{5} \mathrm{O}_{12}:(\mathrm{Tb}, \mathrm{Gd})$ were studied. (C) 2007 American Institute of Physics. [DOI: 10.1063/1.2784998]
\end{abstract}

\section{INTRODUCTION}

During the last decade, more and more attention has been paid to the research on phosphors excitable by vacuum ultraviolet (VUV) radiations because of the development of mercury-free lamps and plasma display panels (PDPs). ${ }^{1-5}$ In both devices, phosphor converts the VUV light (147 nm line and $172 \mathrm{~nm}$ band) from $\mathrm{Xe} / \mathrm{Ne}$ gas discharge ${ }^{3}$ into visible light. Such devices require phosphors with high quantum efficiencies and long lifetime together with suitable fluorescence decay times (especially for PDPs). ${ }^{2}$

It is well known that luminescence efficiency widely depends on the particles morphology of phosphors, which relies on the synthesis route used. ${ }^{6,7}$ Furthermore, especially when excited by VUV radiations, the influence of the host lattice is significant. ${ }^{2,3,5}$ Consequently, research has been developed toward either original host materials or soft chemical methods for which particles morphology seems tunable. ${ }^{3,6,8-11}$

Yttrium aluminum garnet $\left(\mathrm{Y}_{3} \mathrm{Al}_{5} \mathrm{O}_{12}=\mathrm{YAG}\right)$ shows a broad absorption band in the VUV region, associated with excellent chemical and mechanical stabilities under electronic bombardment. ${ }^{12}$ As a result, when activated by rareearth ions, it represents a very promising candidate as phosphor in plasma-based devices. ${ }^{13-19}$ Among the numerous synthesis routes developed to obtain luminescent YAG based materials (solid-state reaction, co-precipitation, spray pyrolysis, sol-gel,...), ${ }^{7,16-20}$ we have chosen to achieve them by the sol-gel process from alkoxide precursors. ${ }^{21,22}$ Indeed, materials resulting from this process exhibit better purity, high degree of homogeneity, and particles of narrow size distribution, ${ }^{6,23}$ which should enhance the absorption of VUV energy. ${ }^{6}$

In this article, $\mathrm{Y}_{3} \mathrm{Al}_{5} \mathrm{O}_{12}: \mathrm{Tb}^{3+}$ and $\mathrm{Y}_{3} \mathrm{Al}_{5} \mathrm{O}_{12}: \mathrm{Ce}^{3+}$ powders were synthesized by the sol-gel process. The purity of derived materials was investigated by means of $\mathrm{x}$-ray diffraction (XRD). Since optical properties of phosphors are largely

${ }^{a)}$ Electronic mail: genevieve.chadeyron@univ-bpclermont.fr influenced by their morphology, their crystallite sizes were determined from XRD analysis, and micrographs were carried out by means of scanning electron microscopy (SEM). To check the potentialities of these phosphors in mercuryfree fluorescent tubes or PDPs,${ }^{24}$ excitation spectra were recorded in the VUV region for both $\mathrm{Ce}^{3+}$ and $\mathrm{Tb}^{3+}$ doped samples. Emission spectra under VUV radiations $\left(\lambda_{e x c}=173\right.$ or $180 \mathrm{~nm}$ ) were also carried out at room temperature (RT) and at $8.2 \mathrm{~K}$. Additionally, decay times of $\mathrm{Ce}^{3+}$ activated samples were measured. Finally, the influence of codoping $\left(\mathrm{Tb}^{3+}, \mathrm{Ce}^{3+}\right.$ and $\left.\mathrm{Tb}^{3+}, \mathrm{Gd}^{3+}\right)$ on optical properties of YAG: $\mathrm{Tb}(20 \mathrm{~mol} \%)$ samples was evaluated.

\section{EXPERIMENTAL PROCEDURE}

\section{A. Modus operandi}

Undoped or terbium or cerium doped $\mathrm{Y}_{3} \mathrm{Al}_{5} \mathrm{O}_{12}$ powders were achieved via a synthesis procedure already described. $^{21,22}$ The influence of codoping has been assessed by studying YAG: $\mathrm{Tb}(20 \%), \mathrm{Ce}(1 \%)$ and $(\mathrm{Y}, \mathrm{Gd}) \mathrm{AG}: \mathrm{Tb}(20 \%)$ (with $n_{\mathrm{Y}} / n_{\mathrm{Gd}}=7 / 3$ ). These doping rates in cerium and terbium have been chosen since they have been determined to be the optimal concentrations of lanthanide ions under blue excitation. ${ }^{22}$

The synthesis was carried out under anhydrous conditions in a dry argon atmosphere since moisture significantly affects alkoxide stability. Experimentally, two solutions were prepared: solution A consisting of anhydrous yttrium chloride $[(3-x)$ molar equivalent, $99.99 \%$ pure, Aldrich] and terbium anhydrous chloride ( $x$ eq., $99.99 \%$ pure, Aldrich) dissolved in anhydrous isopropanol $\left({ }^{i} \mathrm{PrOH}, 99.8+\%\right.$ pure, Aldrich), and solution B of potassium isopropoxide (metallic potassium, 9 eq., $98 \%$ pure, Aldrich, $\left.{ }^{i} \mathrm{PrOH}\right)$. Chunks of potassium need to be carefully cleaned by removing a superficial crust prior to the addition of isopropanol.

Solution B is slowly added to solution A with vigorous stirring, the reaction is highly exothermic, and $\mathrm{KCl}$ is immediately formed. After a $1 \mathrm{~h}$ reflux of the mixed solutions 
at $85^{\circ} \mathrm{C}$, a powder of aluminum isopropoxide (5 eq., $99.99+\%$ pure, Aldrich) was added directly to the solution. A homogeneous solution was obtained after further refluxing $\left(85^{\circ} \mathrm{C}\right)$ and vigorously stirring for $4 \mathrm{~h}$. After cooling, $\mathrm{KCl}$ was separated by centrifuging and a clear sol was collected. Afterwards the sol was hydrolyzed by introducing an excess of water, resulting in a transparent gel that was further dried at $80{ }^{\circ} \mathrm{C}$ to yield a white xerogel. The latter was annealed in a muffle furnace for $4 \mathrm{~h}$ at $800{ }^{\circ} \mathrm{C}$ or $1100{ }^{\circ} \mathrm{C}$.

For samples containing $\mathrm{Gd}^{3+}$ and $\mathrm{Ce}^{3+}$ ions, the precursors used were gadolinium and cerium chlorides (Aldrich, $\mathrm{GdCl}_{3} 99.99 \%$ and $\mathrm{CeCl}_{3} 99.99+\%$, respectively).

\section{B. Characterization techniques}

XRD measurements were performed on a Siemens D500 operating with the $\mathrm{Cu} K \alpha$ radiation $(\lambda=1.5406 \AA)$. SEM micrographs were recorded by means of a ZEISS Supra 55VP operating in high vacuum at $4 \mathrm{kV}$, using a secondary electron detector (Everhart-Thornley detector). Specimens were powdered onto the surface of an adhesive carbon film.

Measurements of excitation and emission spectra as well as decay times in the VUV range were performed at the Deutsches Elektronen Synchotron (DESY, Hamburg) using the facility of SUPERLUMI station ${ }^{25}$ at HASYLAB. The experiments were carried out at room temperature (RT) or at $8.2 \mathrm{~K}$.

Emission spectra were recorded within 300-900 nm range using a $0.3 \mathrm{~m}$ Czerny-Turner-type secondary monochromator-spectrograph SpectraPro-308 (Acton Research Corporation) equipped with a liquid nitrogen cooled CCD detector (Princeton Instruments). For excitation spectra and time-resolved measurements, the luminescence was detected by a HAMAMATSU R6358P PMT photomultiplier (200-800 $\mathrm{nm}$ range). Luminescence excitation spectra were scanned with the primary $2 \mathrm{~m}$ monochromator in $15^{\circ}$ McPherson mounting (resolution of $3.2 \AA$ ). A single photon counting method provided the possibility to accumulate the luminescence decay curve within 0-200 ns range (period of the excitation pulse repetition in five bunch mode of DORIS storage ring operation) and use the time-resolved luminescence technique. Integrated spectra correspond to the total signal formed by the photomultiplier. Luminescence excitation spectra have been corrected on the incident photon flux.

\section{RESULTS AND DISCUSSION}

\section{A. Powder x-ray diffraction}

The XRD patterns of the sol-gel derived undoped YAG, YAG: $\mathrm{Tb}(20 \mathrm{~mol} \%)$, and YAG: $\mathrm{Ce}(1 \mathrm{~mol} \%)$ powders are gathered in Fig. 1. An $800{ }^{\circ} \mathrm{C}$ heating treatment [Fig. 1(a)] leads to a single crystallized phase consistent with YAG since all the diffraction peaks can be assigned to the YAG structure (JCPDS file 33-0040). This crystallization temperature is much lower than that required in solid-state reaction ${ }^{14,17,26}$ and close to the temperatures needed for recent soft chemical routes. ${ }^{18,19,27}$ However, a weak and broad band centered around $32^{\circ}(2 \theta)$ is also observed. It may correspond to an amorphous phase or to an unachieved crystallization of the YAG phase. This latter assumption is con-

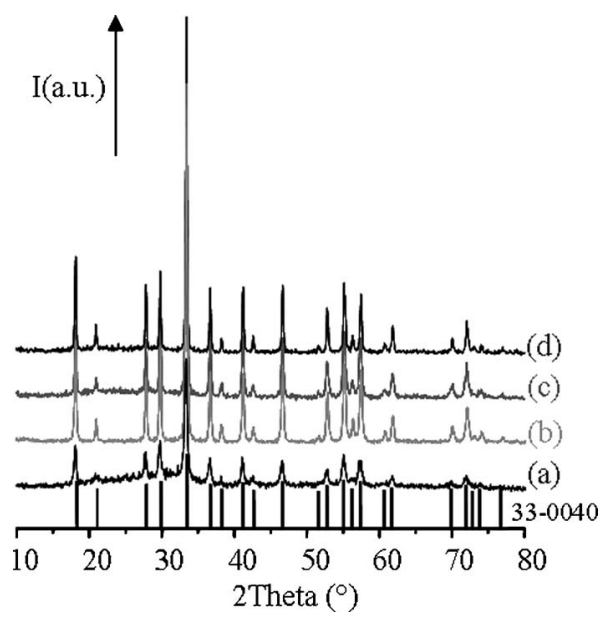

FIG. 1. XRD patterns of undoped YAG powders sintered at (a) $800{ }^{\circ} \mathrm{C}$ and (b) $1100{ }^{\circ} \mathrm{C}$ for $4 \mathrm{~h}$, (c) YAG: $\mathrm{Tb}(20 \mathrm{~mol} \%$ ), and (d) YAG: $\mathrm{Ce}(1 \mathrm{~mol} \%)$ powders heated at $1100{ }^{\circ} \mathrm{C}$ for $4 \mathrm{~h}$. Patterns are compared with the YAG ASTM file 33-0040 represented in dotted lines.

firmed by the disappearance of this band after a sintering at $1100{ }^{\circ} \mathrm{C}$ [Fig. 1(b)]. Indeed, such a sintering treatment entails a better crystallization state characterized by sharper and more well-defined diffraction peaks [Fig. 1(b)]. XRD patterns are not strongly affected when the YAG host is activated by either $20 \mathrm{~mol} \% \mathrm{~Tb}^{3+} \quad[$ Fig. 1(c) $]$ or $1 \mathrm{~mol} \% \mathrm{Ce}^{3+}[$ Fig. $1(\mathrm{~d})]$ since $\mathrm{Y}^{3+}$ and $\mathrm{Tb}^{3+}$ have roughly the same ionic radii.

As detailed in a previous paper, ${ }^{21}$ a $4 \mathrm{~h}$ sinteringtreatment at $1100{ }^{\circ} \mathrm{C}$ was chosen to anneal all the samples since it corresponds to the best conditions so as to provide suitable crystallized YAG to perform optical analyses. As a matter of fact, such a heating treatment leads to the pyrolysis of all organic residues as it was revealed ${ }^{28}$ by infrared and Raman spectroscopies.

\section{B. Samples morphology}

From XRD study, crystallite average sizes of undoped and YAG: $\mathrm{Tb}(20 \%)$ sintered powders have been assessed, applying Scherrer's formula: ${ }^{29}$

$$
\langle D\rangle=\frac{0.9 \lambda}{\beta \times \cos \theta},
$$

where $\langle D\rangle$ is the crystallite average size $(\AA), \lambda$ is the X-ray wavelength $(\lambda=1.5406 \AA$ here, $\mathrm{Cu} K \alpha), \theta$ is the Bragg diffraction angle, and $\beta$ is the full width at half maximum (FWHM).

Figure 2(a) shows the temperature dependence of the mean crystallite size, evaluated from the FWHM of the (420) XRD peak $\left(2 \theta \sim 32^{\circ}\right)$. An increase of the average crystallite size with the heating temperature is observed. The undoped sample calcined at $800{ }^{\circ} \mathrm{C}$ is constituted of $25 \mathrm{~nm}$ particle grains whereas the powder sintered at $1200{ }^{\circ} \mathrm{C}$ is characterized by crystallites for which the diameter is greater than 50 $\mathrm{nm}$. It can be also noticed that the incorporation of rare earth ions $\left(\mathrm{Tb}^{3+}\right)$ entails a grain's enlargement only for the samples 

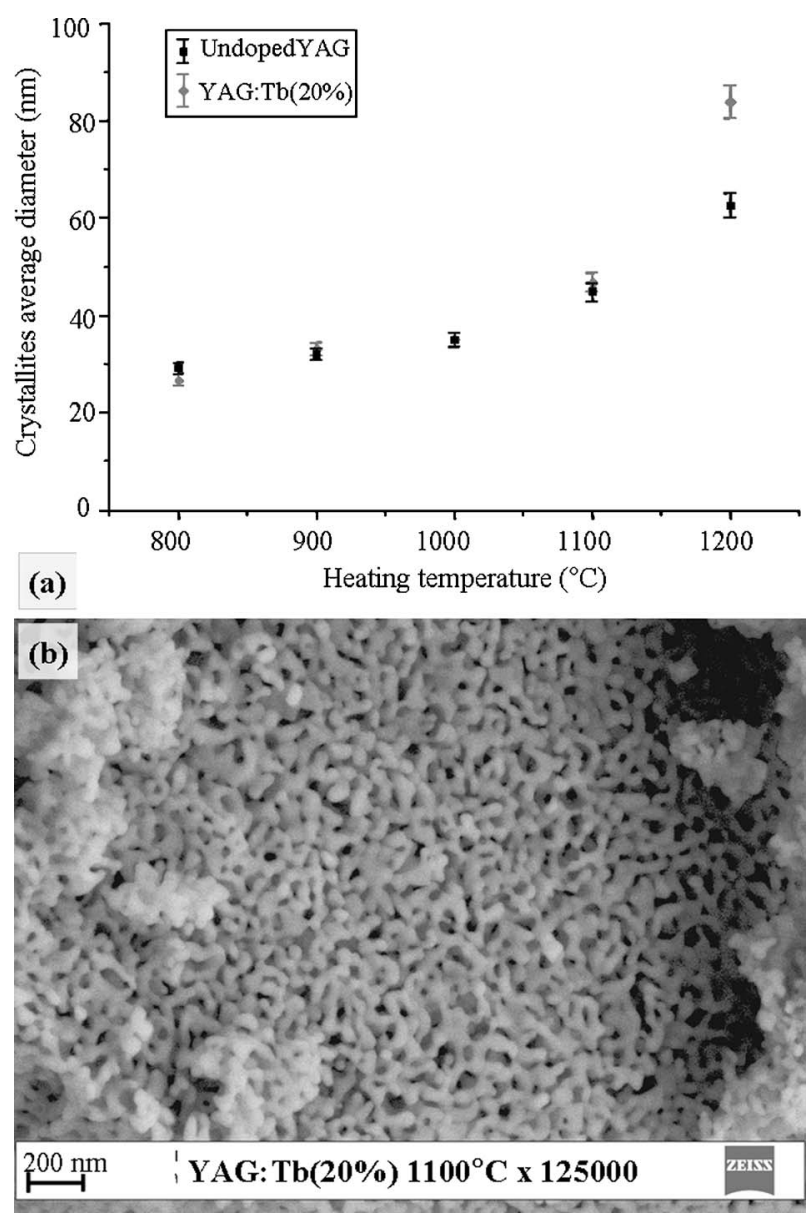

FIG. 2. (a) Temperature dependence of mean crystallite diameters for YAG: $\mathrm{Tb}(20 \%)$ powders; (b) SEM micrograph recorded at $125000 \times$ magnification from YAG: $\mathrm{Tb}(20 \%)$ annealed at $1100{ }^{\circ} \mathrm{C}$ for $4 \mathrm{~h}$.

heated at $1200{ }^{\circ} \mathrm{C}$ : terbium-doped powder exhibits a mean crystallite size near $75 \mathrm{~nm}$ versus $55 \mathrm{~nm}$ for the undoped specimen.

Figure 2(b) represents a SEM micrograph recorded from the YAG: $\mathrm{Tb}(20 \%)$ powder calcined at $1100{ }^{\circ} \mathrm{C}$. It can be seen as a regular nanostructured network that can be qualified as "sponge-like." Primary particles are not easily distinguishable and the network is characterized by a nanoporosity.

\section{Optical properties of YAG: $\mathrm{Tb}^{3+}$ samples}

In order to assess their application potentialities in devices based on the plasma technology, excitation spectra of YAG: Tb samples in the VUV range have been recorded at room temperature, monitoring the ${ }^{5} D_{4} \rightarrow{ }^{7} F_{5}$ transition located at $544 \mathrm{~nm}$.

Excitation spectra obtained from YAG crystallized powders containing 1 and $20 \mathrm{~mol} \%$ of terbium are shown in Fig. 3. These samples exhibit a broad band centered around 170 $\mathrm{nm}$, overlapping the Xe-Ne plasma emission. This corresponds to the band absorption of the host lattice $3,16,17,19,30$ since the band gap energy of YAG is approximately $7.0 \mathrm{eV}$. This band originates from a partial transfer of the energy absorbed by the host to the luminescent center. ${ }^{16} \mathrm{~A}$ slight shift toward the UV range is observed when increasing the

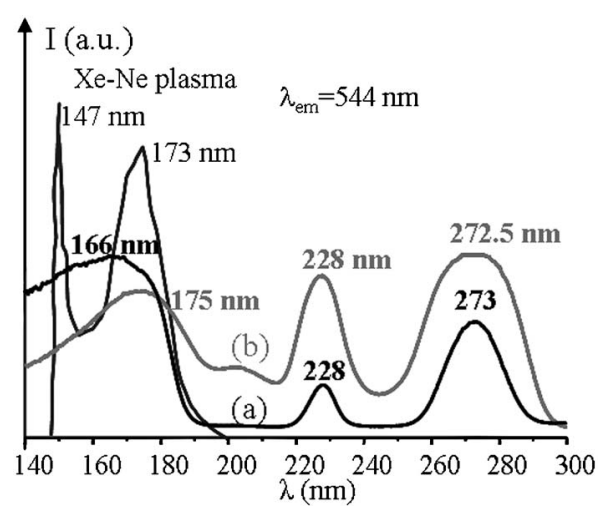

FIG. 3. Room temperature excitation spectra of crystallized YAG: $\mathrm{Tb}(x \mathrm{~mol} \%)$ powders [(a) $x=1$ and (b) $x=20]$ in VUV range monitored at $544 \mathrm{~nm}$.

terbium concentration, corresponding to the substitution of yttrium by a slightly larger ion $\left(r_{\mathrm{Y}}^{3+}=1.02 \AA\right.$ and $r_{\mathrm{Tb}}^{3+}$ $=1.04 \AA$ in coordination VIII). ${ }^{31}$ This trend has already been observed for $\mathrm{Eu}^{3+}\left(r_{\mathrm{Eu}}^{3+}=1.066 \AA \text { in coordination VIII }\right)^{31}$ doped YAG phosphors. ${ }^{19}$ It suggests that tuning the absorption band relative to the host is possible by varying the rareearth ion concentration.

Besides, three other absorption bands are observed: a very weak signal around $200 \mathrm{~nm}$ and two relatively broad bands located at 228 and $273 \mathrm{~nm}$. Whereas the host sensitization band is more intense when YAG contains $1 \mathrm{~mol} \% \mathrm{~Tb}^{3+}$, these bands are stronger and broader when YAG is doped with $20 \mathrm{~mol} \%$ of $\mathrm{Tb}^{3+}$. These bands can be attributed to the excitation of the electron ground state to the split $5 d$ energy levels. ${ }^{10,13,16,18}$ Indeed, $\mathrm{Tb}^{3+}$ ions exhibit a $4 f^{8}$ electron configuration for which the ground state is ${ }^{7} F_{6}$. The $4 f^{7} 5 d$ excitation levels present two spin states: the high spin ${ }^{9} D_{I}$ (or ${ }^{9} E$ ) and the low $\operatorname{spin}{ }^{7} D_{I}$ (or $\left.{ }^{7} E\right)^{18}(I$ $=0, \ldots, 5)$. Regarding Hund's rule, ${ }^{32}$ the ${ }^{7} E$ levels are higher than the ${ }^{9} E$ ones. As a consequence, excitation spectra of a $\mathrm{Tb}^{3+}$ doped host generally present two groups of absorption bands: the first, corresponding to spin-allowed $f-d$ transitions, is located at high energy (low wavelength) and the second, related to spin-forbidden transitions, is situated at low energy (high wavelength). The bands centered at 228 and $273 \mathrm{~nm}$ present a relatively strong intensity and thus seem to be related to the allowed transitions ${ }^{7} F_{6} \rightarrow{ }^{7} D_{I}$. In agreement with the recent work of Dorenbos, ${ }^{33}$ these bands can be ascribed to ${ }^{7} F_{6} \rightarrow{ }^{7} D_{5}$ and ${ }^{7} F_{6} \rightarrow{ }^{7} D_{4}$ transitions, respectively. The weak signal distinguished around $200 \mathrm{~nm}$ is also attributed to the $4 f \rightarrow 5 d$ transitions of $\mathrm{Tb}^{3+}$ ion, more precisely to the prohibited transition ${ }^{7} F_{6} \rightarrow{ }^{9} D_{3}$. The intensity of this transition increases with terbium concentration but remains weak in comparison with the two other excitation bands observed at lower energy. ${ }^{13,16}$

Emission spectra recorded for the same samples under $180 \mathrm{~nm}$ excitation are gathered in Fig. 4. For the lowest concentration of $\mathrm{Tb}^{3+}$ [Fig. 4(a)], the spectrum can readily be divided into two groups of lines: the blue emission below $480 \mathrm{~nm}$ is related to ${ }^{5} D_{3} \rightarrow{ }^{7} F_{J}$ transitions whereas the green emission arises from ${ }^{5} D_{4} \rightarrow{ }^{7} F_{J}$ ( $J=6$ to 0$)$ transitions. ${ }^{34-37}$ When the terbium concentration reaches $20 \mathrm{~mol} \%$ [Fig. 


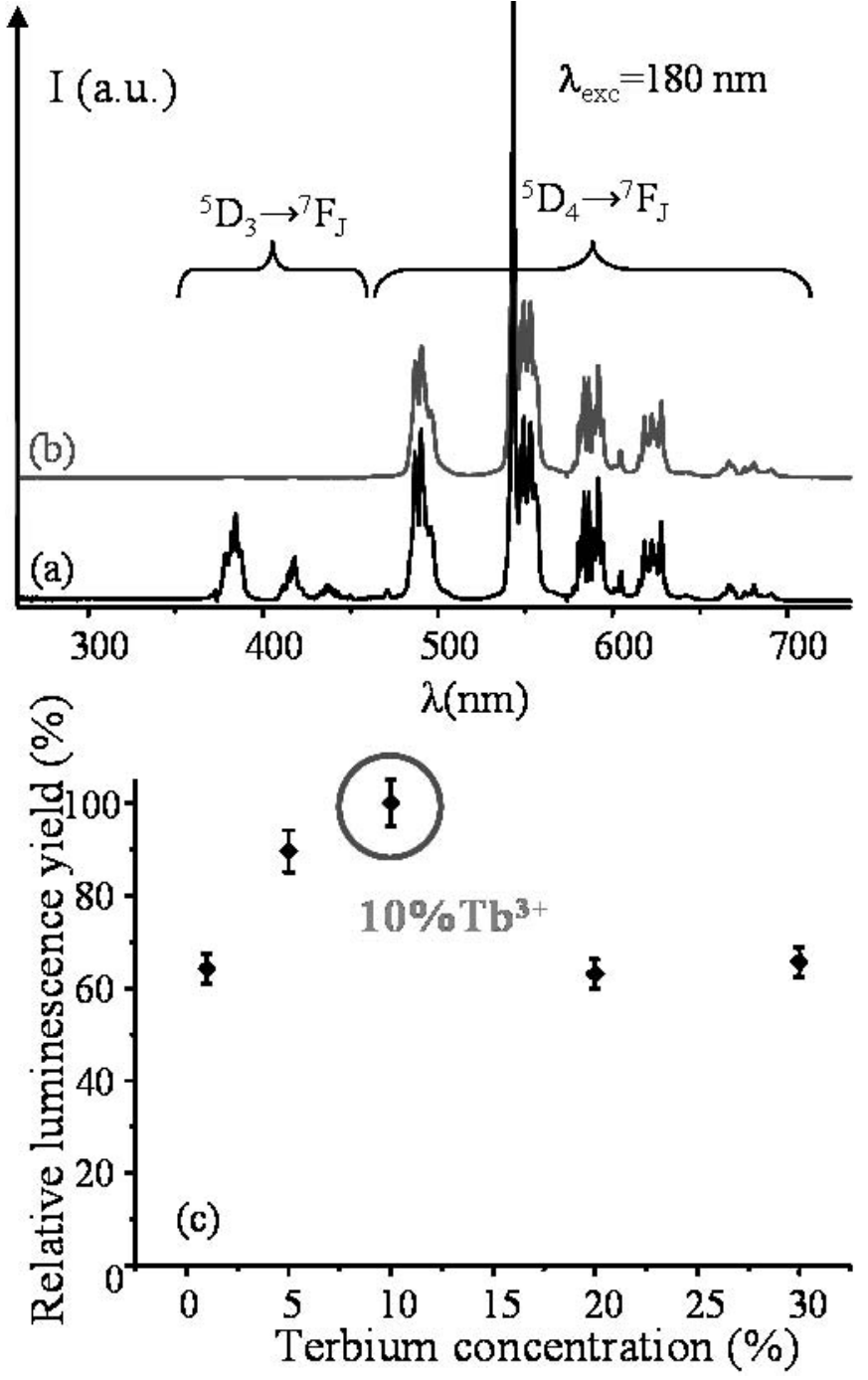

FIG. 4. Room temperature emission spectra of crystallized YAG: $\operatorname{Tb}(x \mathrm{~mol} \%)$ powders [(a) $x=1$ and (b) $x=20$ ] and (c) concentration dependence of $\mathrm{Tb}^{3+}$ emission intensity of ${ }^{5} D_{4} \rightarrow{ }^{7} F_{5}$ transition upon $180 \mathrm{~nm}$ excitation.

4(b)], the blue emission disappears: only ${ }^{5} D_{4} \rightarrow{ }^{7} F_{J}$ transitions are recorded. Such observation corresponds to the wellknown cross relaxation phenomenon ${ }^{34,35}$ observed under UV or blue excitation. ${ }^{22,34,37}$ It can be summarized by the following equation: ${ }^{2,37}$

$$
\mathrm{Tb}^{3+}\left({ }^{5} D_{3}\right)+\mathrm{Tb}^{3+}\left({ }^{7} F_{6}\right) \rightarrow \mathrm{Tb}^{3+}\left({ }^{5} D_{4}\right)+\mathrm{Tb}^{3+}\left({ }^{7} F_{0}\right) .
$$

Besides, the most efficient doping rate has been determined by integrating the area of the ${ }^{5} D_{4} \rightarrow{ }^{7} F_{5}$ transition located at $544 \mathrm{~nm}$. Results are shown in Fig. 4(c). On this basis, the higher luminescence yield upon VUV excitation is obtained for $10 \mathrm{~mol} \%$ of $\mathrm{Tb}^{3+}$. Above it, concentration quenching

occurs. Interestingly, this optimal doping rate is different from that determined under blue excitation, which was $20 \mathrm{~mol}^{22} .^{22}$

These results, combined with a decay time lying between 3 and $10 \mathrm{~ms},{ }^{21}$ make YAG: $\mathrm{Tb}^{3+}$ samples suitable phosphors for application in devices based on plasma excitation. ${ }^{2}$

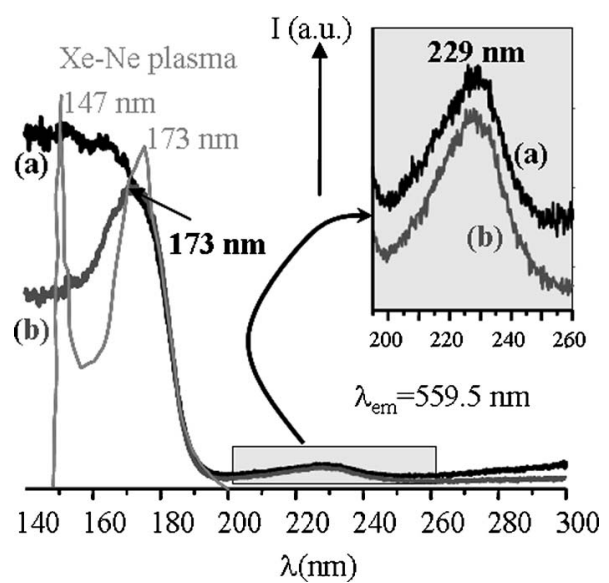

FIG. 5. Room temperature excitation spectra of crystallized YAG: $\mathrm{Ce}(x$ mol \%) powders [(a) $x=0.5$ and (b) $x=2$ ] in VUV range monitored at $559.5 \mathrm{~nm}$.

\section{Optical properties of YAG: $\mathrm{Ce}^{3+}$ samples}

Excitation spectra recorded at room temperature monitoring the broad emission band centered at about $560 \mathrm{~nm}$ (Ref. 37) are presented in Fig. 5. As in the case of terbium doped samples, a broad band corresponding to the matrix absorption is observed within the Xe-Ne plasma emission range. Furthermore, another weak absorption signal situated at about $229 \mathrm{~nm}$ (see the inset) is observed, corresponding to $4 f^{1} \rightarrow 5 d^{1}$ electron transitions. ${ }^{38}$

When excited by a VUV source, samples exhibit the characteristic yellowish green emission of $\mathrm{Ce}^{3+}$ in a YAG host, ${ }^{37}$ as one can see in Fig. 6. At room temperature, only a broad band lying between 470 and $710 \mathrm{~nm}$ is observed [(Fig. 6(a)] while at $8.2 \mathrm{~K}$ two signals are well distinguished [Fig. 6(b)], originating from the transition of $5 d$ levels to the ground state consisting of a doublet $\left({ }^{2} F_{5 / 2}\right.$ and $\left.{ }^{2} F_{7 / 2}\right){ }^{37,38}$ Results of the Gaussian fit applied to the emission spectrum recorded at low temperature are gathered in Table I. The energy difference between these two signals $\left(1897 \mathrm{~cm}^{-1}\right)$ is concordant with the ground state configuration of $\mathrm{Ce}^{3+}$, for which the two levels are separated by almost $2000 \mathrm{~cm}^{-1}$ due to spin-orbit coupling. ${ }^{36-38}$

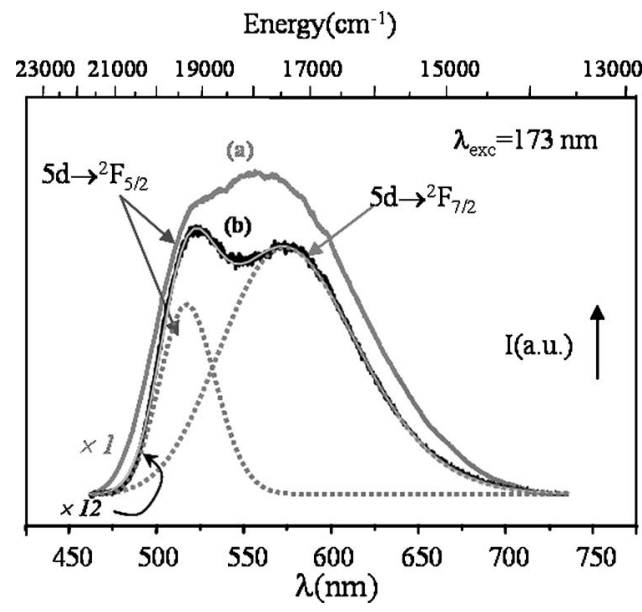

FIG. 6. Emission spectra of crystallized YAG: $\mathrm{Ce}(0.5 \mathrm{~mol} \%)$ powders recorded upon $173 \mathrm{~nm}$ excitation at (a) room temperature and (b) $8.2 \mathrm{~K}$ (solid line) associated with corresponding fitted Gaussian curves (dot lines). 
TABLE I. Parameters describing the Gaussian fit of the $5 d \rightarrow 4 f$ emissions of $\mathrm{Ce}^{3+}$ in $\mathrm{Y}_{3} \mathrm{Al}_{5} \mathrm{O}_{12}: \mathrm{Ce}^{3+}(0.5 \mathrm{~mol} \%)$ recorded at $8.2 \mathrm{~K}$.

\begin{tabular}{ccc}
\hline \hline Transition & $5 d \rightarrow{ }^{2} F_{5 / 2}$ & $5 d \rightarrow{ }^{2} F_{7 / 2}$ \\
\hline$X\left(\mathrm{~cm}^{-1}\right)$ & 19327 & 17430 \\
Intensity (a.u.) & 3665 & 2813 \\
Width $\left(\mathrm{cm}^{-1}\right)$ & 2355 & 1187 \\
& $\Delta E=1897 \mathrm{~cm}^{-1} R^{2}=0.99912$ \\
\hline
\end{tabular}

Moreover, the most efficient doping rate has been determined by integrating the area of the broad band observed at RT [Fig. 6(a)]. Results are gathered in Fig. 7. On this basis, the most efficient phosphor corresponds to $1 \mathrm{~mol} \%$ of $\mathrm{Ce}^{3+}$. This value is similar to that determined under blue excitation. ${ }^{39}$

Finally, the decay curves of the sample doped with $0.5 \mathrm{~mol} \%$ of Ce recorded at RT and at $8.2 \mathrm{~K}$ (monitoring $5 d \rightarrow{ }^{2} F_{5 / 2}$ and $5 d \rightarrow{ }^{2} F_{7 / 2}$ transitions) are presented in Figs. 8(a)-8(c). They can be well fitted by a double exponential decay, which is composed of a short component and a longer one. The latter is related to a retrapping phenomenon of migrating electrons and holes, which entails a delayed recombination at $\mathrm{Ce}^{3+}$ centers. ${ }^{40}$ It is a commonly encountered phenomenon in $\mathrm{Ce}^{3+}$-doped crystals under gamma excitation ${ }^{41}$ and has already been observed in YAG: $\mathrm{Ce}^{3+}$ crystals $^{42}$ and ceramics. ${ }^{40}$ Time constants of decays are collected in Table II. Interestingly, for the measurements carried out at RT, the values of the two components are in agreement with that determined by Zych et $a l .{ }^{42}$ at RT under $178 \mathrm{~nm}$ excitation in crystals (68 versus $85 \mathrm{~ns}$ and 354 versus $320 \mathrm{~ns}$ for the shorter and longer components, respectively).

\section{E. Influence of codoping}

Since it is known that $\mathrm{Ce}^{3+}$ or $\mathrm{Gd}^{3+}$ can be used as sensitizers for $\mathrm{Tb}^{3+}$ ions, ${ }^{10,12,17,38,43}$ the influence of $\mathrm{Y}^{3+}$ substitution by these ions, keeping the terbium concentration at $20 \mathrm{~mol} \%$, has been investigated.

Figure 9 shows the excitation spectra of YAG: $\mathrm{Tb}(20 \mathrm{~mol} \%), \quad(\mathrm{Y}, \mathrm{Gd}) \mathrm{AG}: \mathrm{Tb}(20 \mathrm{~mol} \%)$ and YAG: $\mathrm{Tb}(20 \mathrm{~mol} \%), \mathrm{Ce}(1 \mathrm{~mol} \%)$ in the VUV range. Gadolinium allows shifting the host band at lower energy, re-

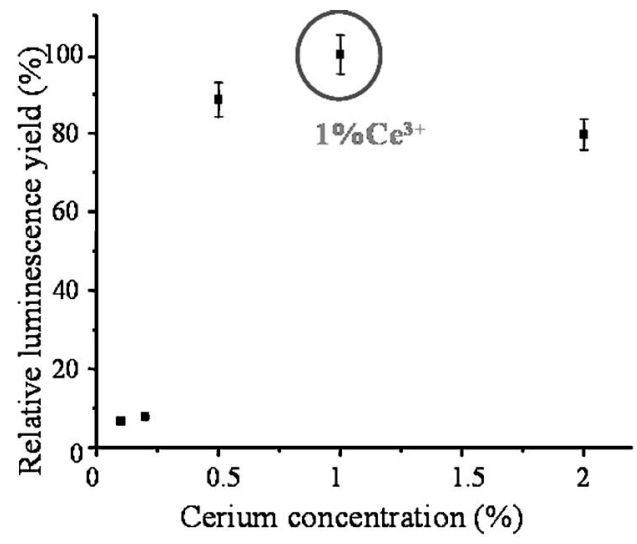

FIG. 7. Concentration dependence of $\mathrm{Ce}^{3+}$ emission intensity of $5 d \rightarrow 4 f$ transitions upon $173 \mathrm{~nm}$ excitation.

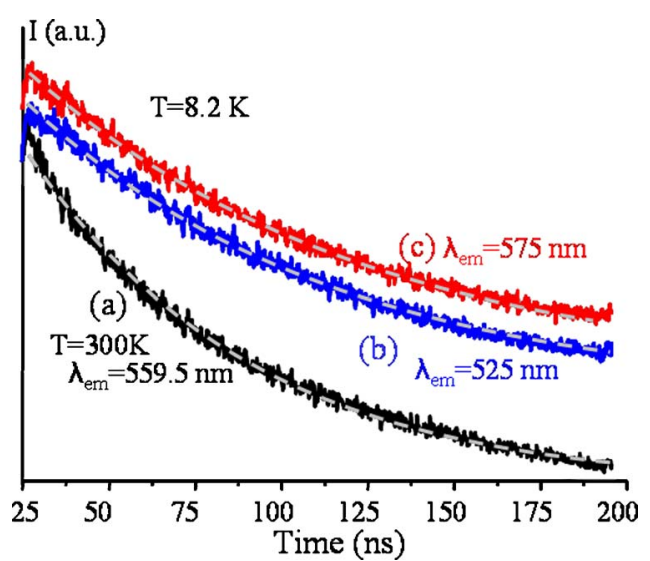

FIG. 8. (Color online) Luminescence decay traces of the $5 d \rightarrow 4 f$ emissions of $\mathrm{Ce}^{3+}$ in $\mathrm{Y}_{3} \mathrm{Al}_{5} \mathrm{O}_{12}: \mathrm{Ce}^{3+}(0.5 \mathrm{~mol} \%)$ at (a) RT and (b), (c) $8.2 \mathrm{~K}$ upon 173 $\mathrm{nm}$ excitation associated with corresponding fitted double exponential curves (dashed lines).

sulting in a better overlapping with the Ne-Xe plasma emission [Fig. 9(b)]. This trend has already been observed in borates ${ }^{3}$ and may be due to the increase of $\mathrm{Ln}^{3+}$ radius when $\mathrm{Y}$ is substituted by $\mathrm{Gd}\left(r_{\mathrm{Y}}^{3+}=1.02 \AA\right.$ and $r_{\mathrm{Gd}}^{3+}=1.053 \AA$ in coordination VIII). ${ }^{31}$ Moreover, the powder codoped with cerium and terbium leads to a weak absorption in the VUV range [Fig. 9(c)]. It is also noteworthy that $\mathrm{Gd}^{3+}$ enhances the intensity of excitation bands whereas $\mathrm{Ce}^{3+}$ makes it decrease significantly.

On the other hand, emission spectra of the same samples excited at $180 \mathrm{~nm}$ are also gathered in Fig. 9: the presence of gadolinium increases significantly the emission intensity [Fig. 9(b)], indicating an efficient energy transfer from host lattice to $\mathrm{Tb}^{3+}$ with $\mathrm{Gd}^{3+}$ as an intermediate. In the case of cerium [Fig. 9(c)], the emission spectrum exhibits typical transitions of both $\mathrm{Ce}^{3+}$ and $\mathrm{Tb}^{3+}$ ions, indicating a weak energy transfer from $\mathrm{Ce}^{3+}$ to $\mathrm{Tb}^{3+}$. Meanwhile, when adding $1 \mathrm{~mol} \%$ of $\mathrm{Ce}$, the emission intensity drops drastically. Such behaviors have already been brought out in $\mathrm{YAG}^{17}$ and in other matrices. ${ }^{10,43}$

\section{CONCLUSION}

To conclude, we have shown that the sol-gel process is a convenient route to synthesize monophased YAG powders from $800{ }^{\circ} \mathrm{C}$, which represents a much lower crystallization temperature compared to the solid state synthesis. Furthermore, optical study has revealed wide absorption bands located in the VUV range, which entails the potential utilization of YAG based materials in applications using VUV

TABLE II. Parameters describing shape of decay traces of the $5 d \rightarrow 4 f$ emissions of $\mathrm{Ce}^{3+}$ in $\mathrm{Y}_{3} \mathrm{Al}_{5} \mathrm{O}_{12}: \mathrm{Ce}^{3+}(0.5 \mathrm{~mol} \%)$ fitting by a double exponential curve.

\begin{tabular}{l|c|c|c}
\hline \hline \multirow{2}{*}{} & $T=300 \mathrm{~K}$ & \multicolumn{2}{|c}{$T=8.2 \mathrm{~K}$} \\
\cline { 2 - 4 } & \multicolumn{3}{|c}{$\lambda_{e x c}=173 \mathrm{~nm}$} \\
\cline { 2 - 4 } & $\lambda_{e m}=559.5 \mathrm{~nm}$ & $\lambda_{e m}=525 \mathrm{~nm}$ & $\lambda_{e m}=575 \mathrm{~nm}$ \\
\hline$\tau_{1}(\mathrm{~ns})$ & 68 & 103 & 94 \\
$\tau_{2}(\mathrm{~ns})$ & 354 & 909 & 847 \\
\hline \hline
\end{tabular}




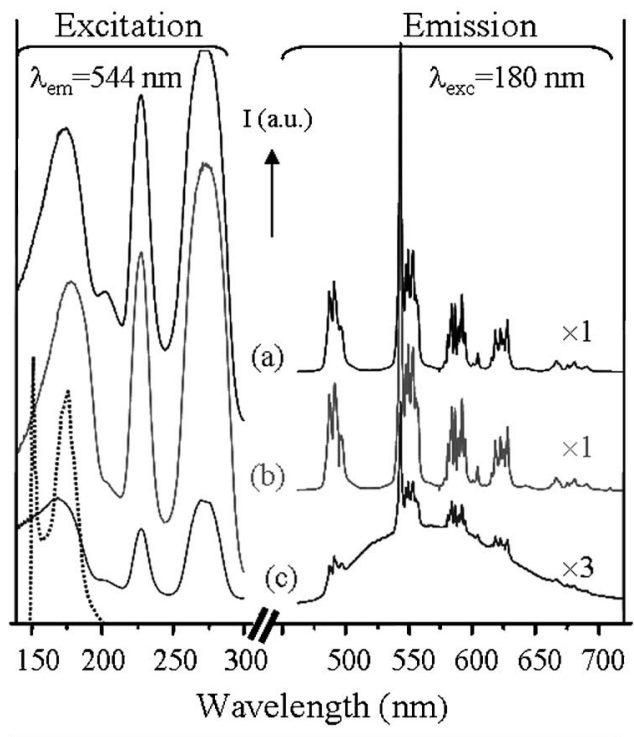

............ Xe-Ne plasma emission

FIG. 9. Room temperature excitation $\left(\lambda_{e m}=544 \mathrm{~nm}\right)$ and emission $\left(\lambda_{e x c}\right.$ $=180 \mathrm{~nm})$ spectra of crystallized (a) YAG: $\mathrm{Tb}(20 \mathrm{~mol} \%)$, (b) (Y, Gd)AG: $\mathrm{Tb}(20 \mathrm{~mol} \%)$, and (c) YAG:Tb(20 $\mathrm{mol} \%), \mathrm{Ce}(1 \mathrm{~mol} \%)$ powders.

excitations such as PDPs or free Hg lamps. The optimal doping rates of $\mathrm{Tb}^{3+}$ and $\mathrm{Ce}^{3+}$ ions in YAG have been determined to be 10 and $1 \mathrm{~mol} \%$, respectively. As it has been noticed, these results are not the same as those obtained under blue excitation. This points out the relevance of adjusting the rare-earth concentration according to the excitation source used.

On the basis of this work undertaken on rare-earth activated YAG matrices, it appeared that $\mathrm{Ce}^{3+}$ ions quenched $\mathrm{Tb}^{3+}$ luminescence whereas the presence of $\mathrm{Gd}^{3+}$ entailed a sensitive enhancement of emission intensity under VUV radiation. Further investigations on codoping effects have to be carried out to obtain enough efficient phosphors for use in devices.

\section{ACKNOWLEDGMENTS}

The authors acknowledge DESY and the European Community, respectively, for the access of VUV spectroscopy facilities and the financial support (Contract No. RII3-CT2004-506008). They are also grateful to G. Stryganyuck for technical expertise during VUV measurements.

${ }^{1}$ T. Jüstel, H. Nikol, and C. R. Ronda, Angew. Chem. Int. Ed. 37, 3084 (1998).

${ }^{2}$ R. P. Rao, J. Electrochem. Soc. 150, H165 (2003).

${ }^{3}$ C. H. Kim, I. E. Kwon, C. H. Park, Y. J. Hwang, H. S. Bae, B. Y. Yu, C.

H. Pyun, and G. Y. Hong, J. Alloys Compd. 311, 33 (2000).

${ }^{4}$ M. Zachau and A. Konrad, Solid State Phenom. 99-100, 13 (2004).

${ }^{5}$ K. Toda, J. Alloys Compd. 408-412, 665 (2006).

${ }^{6}$ W. Di, X. Wang, B. Chen, H. Lai, and X. Zhao, Opt. Mater. 27, 1386 (2005).

${ }^{7}$ Y. C. Kang, I. W. Lenggoro, S. B. Park, and K. Okuyano, J. Phys. Chem.
Solids 60, 1855 (1999).

${ }^{8}$ L. Zhou, W. C. H. Choy, J. Shi, M. Gong, and H. Liang, Mater. Chem. Phys. 100, 372 (2006).

${ }^{9}$ L. Zhou, W. C. H. Choy, J. Shi, M. Gong, H. Liang, and T. I. Yuk, J. Solid State Chem. 178, 3004 (2005).

${ }^{10}$ D. Zhou, D. He, Z. Liang, and T. Hou, J. Lumin. 122-123, 993 (2007).

${ }^{11}$ D. Boyer and R. Mahiou, Chem. Mater. 16, 2518 (2004).

${ }^{12}$ G. W. Berkstresser, J. Smulovich, T. C. D. Huo, and G. Matulis, J. Electrochem. Soc. 134, 2624 (1987).

${ }^{13}$ C. H. Park, S. J. Park, B. Y. Yu, H. S. Bae, C. H. Kim, C. H. Pyun, and G. Y. Hong, J. Mater. Sci. Lett. 19, 335 (2000).

${ }^{14}$ S. Shionoya, Phosphor Handbook (CRC, Boca Raton, FL, 1998) pp. 394 and 515 .

${ }^{15}$ D. S. Hamilton, S. K. Gayen, G. J. Pogatshnik, R. D. Ghen, and W. J. Miniscalco, Phys. Rev. B 39, 8807 (1989).

${ }^{16}$ A. Mayolet, W. Zhang, E. Simoni, J. C. Krupa, and P. Martin, Opt. Mater. 4, 757 (1995).

${ }^{17}$ Y. S. Lin, R. S. Liu, and B.-M. Cheng, J. Electrochem. Soc. 152, J41 (2005).

${ }^{18}$ R. A. Rodriguez-Rojas, E. De la Rosa-Cruz, L. A. Diaz-Torres, P. Salas, R. Melendrez, M. Barboza-Flores, M. A. Meneses-Nava, and O. BarbosaGarcia, Opt. Mater. 25, 285 (2004).

${ }^{19}$ C.-H. Lu, W.-T. Hsu, and B.-M. Cheng, J. Appl. Phys. 100, 063535 (2006).

${ }^{20}$ D. Ravichandran, R. Roy, A. G. Chakhovskoi, C. E. Hunt, W. B. White, and S. Erdei, J. Lumin. 71, 291 (1997).

${ }^{21}$ A. Potdevin, G. Chadeyron, D. Boyer, B. Caillier, and R. Mahiou, J. Phys. D 38, 3251 (2005).

${ }^{22}$ A. Potdevin, G. Chadeyron, D. Boyer, and R. Mahiou, J. Mater. Sci. 41, 2201 (2006).

${ }^{23}$ C. J. Brinker and G. W. Scherer, Sol-gel Science: The Physics and Chemistry of Sol-gel Processing (Academic, San Diego, 1990).

${ }^{24}$ B. Caillier, Ph. Guillot, J. Galy, R. Mauricot, J. Dexpert-Ghys, and N. Joffin, Proceedings of the 15th International Conference on Gas Discharges and their Applications, GD2004, Toulouse, France, September 2004, D204, pp. 493-497.

${ }^{25}$ G. Zimmerer, Nucl. Instrum. Methods Phys. Res. A 308, 178 (1991).

${ }^{26}$ L. E. Shea Rohwer and R. J. Walko, Handbook of Luminescence, Display Materials and Devices (American Scientific Publishers, Stevenson Ranch, 2003), Vol. 3, pp. 157-209.

${ }^{27}$ E. De la Rosa, L. A. Diaz-Torres, P. Salas, A. Arredondo, J. A. Montoya, and R. A. Rodriguez, Opt. Mater. 27, 1793 (2005).

${ }^{28}$ A. Potdevin, G. Chadeyron, D. Boyer, and R. Mahiou, J. Sol-Gel Sci. Technol. 39, 275 (2006).

${ }^{29}$ B. D. Cullity, Elements of X-ray Diffraction, 2nd ed. (Addison-Wesley, Reading, MA, 1978).

${ }^{30}$ T. Jüstel, J.-C. Krupa, and D. U. Wiechert, J. Lumin. 93, 179 (2001).

${ }^{31}$ R. D. Shannon and C. T. Prewitt, Acta Crystallogr., Sect. B: Struct. Crystallogr. Cryst. Chem. 25, 925 (1969).

${ }^{32}$ E. Nakazawa, J. Lumin. 100, 89 (2002).

${ }^{33}$ P. Dorenbos, J. Phys.: Condens. Matter 15, 6249 (2003).

${ }^{34}$ W. F. Van Der Weg, Th. J. A. Popma, and A. T. Vink, J. Appl. Phys. 57, 5450 (1985).

${ }^{35}$ D. J. Robbins, B. Cockayne, B. Lent, and J. L. Glasper, Solid State Commun. 20, 673 (1976).

${ }^{36}$ G. H. Dieke and H. M. Crosswhite, Appl. Opt. 2, 675 (1963).

${ }^{37}$ G. Blasse and B. C. Grabmaier, Luminescent Materials (Springler-Verlag, Berlin, 1994)

${ }^{38}$ Y. Dong et al., Mater. Res. Bull. 41, 1959 (2006).

${ }^{39}$ A. Potdevin, G. Chadeyron, D. Boyer, and R. Mahiou, Phys. Status Solidi C 4, 65 (2007).

${ }^{40}$ E. Mihokova, M. Nikl, J. A. Mares, A. Beitlerova, A. Vedda, K. Nejezchleb, K. Blazek, and C. D'Ambrosio, J. Lumin. 126, 77 (2007).

${ }^{41}$ A. J. Wojtowicz, J. Glodo, A. Lempicki, and C. Brecher, J. Phys.: Condens. Matter 10, 8401 (1998).

${ }^{42}$ E. Zych, C. Brecher, and J. Glodo, J. Phys.: Condens. Matter 12, 1947 (2000).

${ }^{43}$ H. C. Yang, C. Y. Li, H. He, Y. Tao, J. H. Xu, and Q. Su, J. Lumin. 118, 61 (2006). 